\title{
Correction: Impact of epidural analgesia on the systemic biomarker response after hepatic resection
}

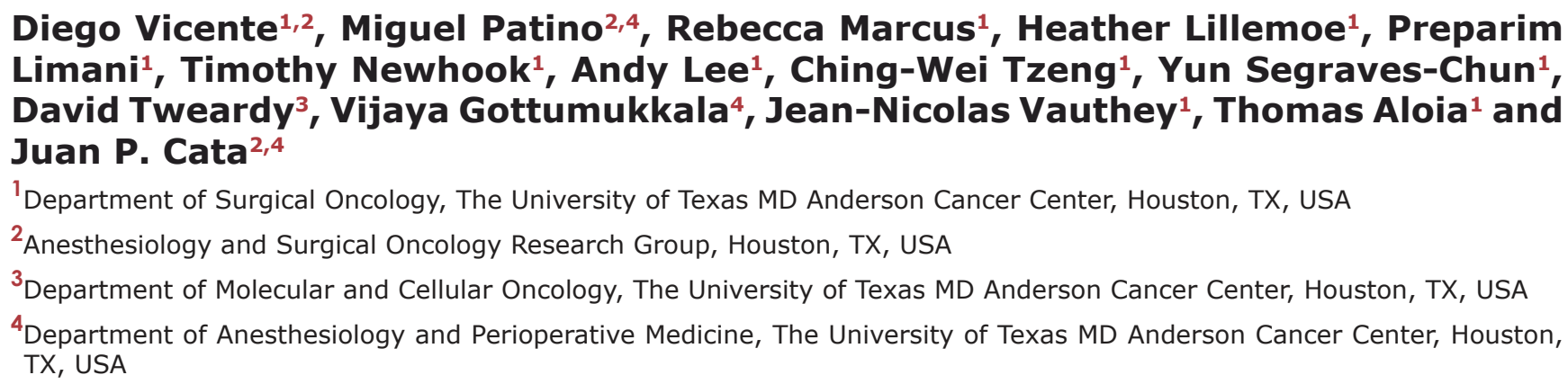

Diego Vicente ${ }^{1,2}$, Miguel Patino ${ }^{2,4}$, Rebecca Marcus ${ }^{1}$, Heather Lillemoe ${ }^{1}$, Preparim Limani $^{1}$, Timothy Newhook ${ }^{1}$, Andy Lee ${ }^{1}$, Ching-Wei Tzeng ${ }^{1}$, Yun Segraves-Chun ${ }^{1}$, David Tweardy ${ }^{3}$, Vijaya Gottumukkala ${ }^{4}$, Jean-Nicolas Vauthey ${ }^{1}$, Thomas Aloia $^{1}$ and Juan P. Cata ${ }^{2,4}$

${ }^{1}$ Department of Surgical Oncology, The University of Texas MD Anderson Cancer Center, Houston, TX, USA

${ }^{2}$ Anesthesiology and Surgical Oncology Research Group, Houston, TX, USA

${ }^{3}$ Department of Molecular and Cellular Oncology, The University of Texas MD Anderson Cancer Center, Houston, TX, USA

${ }^{4}$ Department of Anesthesiology and Perioperative Medicine, The University of Texas MD Anderson Cancer Center, Houston, TX, USA

\section{Published: October 29, 2019}

Copyright: Vicente et al. This is an open-access article distributed under the terms of the Creative Commons Attribution License 3.0 (CC BY 3.0), which permits unrestricted use, distribution, and reproduction in any medium, provided the original author and source are credited.

This article has been corrected: The last name of the 4th author was spelled incorrectly. The proper spelling is given below:

\section{Heather Lillemoe ${ }^{1}$}

Original article: Oncotarget. 2019; 10:584-594. https://doi.org/10.18632/oncotarget.26549 